\title{
Prevalence of Head Injury of Patients Arriving in a Tertiary Care Center.
}

\author{
Arbindra Kumar Yadav' ${ }^{1}$, Jagat Narayan Rajbanshi ${ }^{1}$, Saroj Kumar Kushwaha ${ }^{2}$, Pankaj Raj Nepal ${ }^{1}$ \\ ${ }^{1}$ Department of Neurosurgery, B \& C Medical College and Teaching Hospital \& Research Center, \\ Birtamode, Jhapa, Nepal \\ ${ }^{2}$ Summit Hospital, Lokanthali, Bhaktapur, Nepal. \\ Correspondence: \\ Dr Arbindra Kumar Yadav \\ Department of Neurosurgery, B \& C Medical College and Teaching Hospital \& Research \\ Center,Birtamode,Jhapa,Nepal. \\ Email: arbindrayadav@yahoo.com \\ Phone: +9779814701254
}

\begin{abstract}
Background and purpose: The prevalence of head injury is increasing with increasing number of automobiles, especially motorbike. With the objective to evaluate the prevalence of head injury and factors that could affect the severity of head injury, this study was performed in a tertiary hospital at far- eastern Nepal. Methodology: This is a cross-sectional study over the duration of one year. Association of age, gender, and mode of injury was checked with severity of injury using Chi-square test where P-value was kept significant at $<0.01$. Result: Total numbers of patient admitted through the emergency department, during the study period, were 832. Mean age of patient in the study group was 34.59 (SD 18.92) years. Majority of them falls in the category of 20-29 years. Among the different categories of head injuries, mild head injury (76\%) was the most common presentation followed by moderate head injury and severe head injury, which were $14 \%$ and $10 \%$ respectively. Conclusion: Head injury seems to be the major cause of emergency admission in for eastern part of Nepal. Among them road traffic accidents seems to be the major burden which is more common in young gentlemen with significant number of severe head injury.
\end{abstract}

Key words: head injury, traumatic brain injury, road traffic accidents.

$\mathrm{H}$ ead injury is a worst problem in this globe since last few decades. ${ }^{1-4}$ The prevalence of head injury is increasing with increasing number of automobiles, especially motorbikes. ${ }^{2,3} \mathrm{It}$ seems to be more in developing and developed country. ${ }^{1-4}$ The outcome following head injury is directly associated with severity, mode, and age at the time of injury. ${ }^{5-7}$ With the objective to evaluate the prevalence of head injury and factors that could affect the severity of head injury, this study was performed in a tertiary hospital at far- eastern Nepal.

\section{Material and Methods}

Type of study: Cross-sectional study

Sample technique: Non-probability consecutive sampling.

Duration of study: 1 year (September, 2018 to

October).

Sample size: 832

Site of study: B and C Medical College Teaching Hospital and Research Center, Birtamode, Jhapa, Nepal.

38

Date submitted: $15 / 11 / 2019$

Date accepted: 14/12/2019
Data collection and analysis: All the consecutive trauma patients that landed in emergency department during the study period were collected. The data including age, gender, mode of injury and severity of injury were collected in a preformed proforma.

Age was presented as mean and standard deviation (SD), along with stratification in different decades, and mode of injury. Gender, mode of injury, and severity of injury were presented in percentage.

Association of age, gender, and mode of injury was checked with severity of injury using Chi-square test where $\mathrm{P}$-value was kept significant at $<0.01$.

\section{Results}

Total numbers of patient admitted through the emergency department, during the study period, were 832. Mean age of patient in the study group was 34.59 (SD 18.92) years. Majority of them falls in the category of 20-29 years (Figure-1). There were $74 \%$ male patients followed by $26 \%$ female (Figure-2). Among the head injured patients, Road

egneuro Volume 02, Issue 01, 2020 DOI: https://doi.org10.3126/egn.v2i1.27461 
Traffic Accidents (RTA) accounted for 62\%, which is highest in its category. Mean age of patients with RTA was 35.98 (SD 18.92) years (Table -1).

Among the different categories of head injuries, mild head injury (76\%) was the most common presentation followed by moderate head injury and severe head injury, which were $14 \%$ and $10 \%$ respectively (Figure-4).

Although, male patients seems to be the common population of head injury, it was not significantly association with the severity of head injury. However mode of injury and age were strongly associated with severity of head injury with Pvalue $<0.01$. In this study, RTA and physical assault seems to posses more percentage of severe head injury than due to fall (Table -2). Similarly, increasing age seems to be associated with more percentage of moderate and severe head injury with significant $P$ value (Table-2).

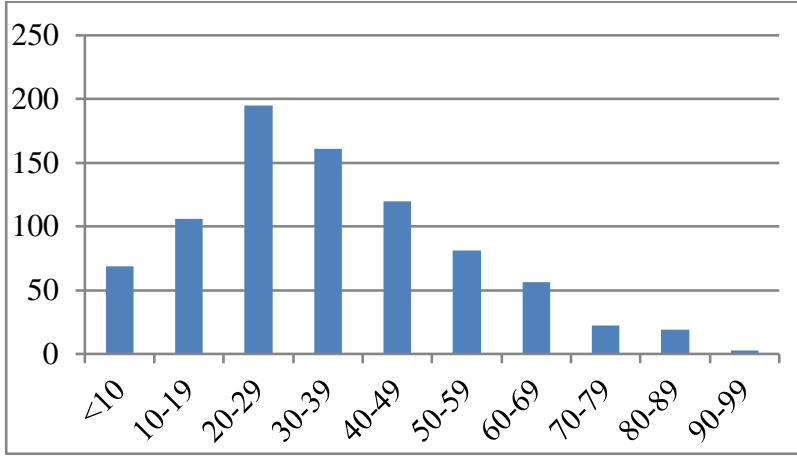

Figure 1: Distribution of different age category

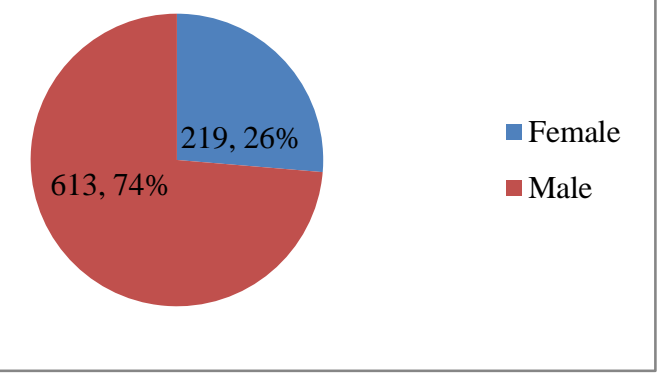

Figure 2: Distribution of gender

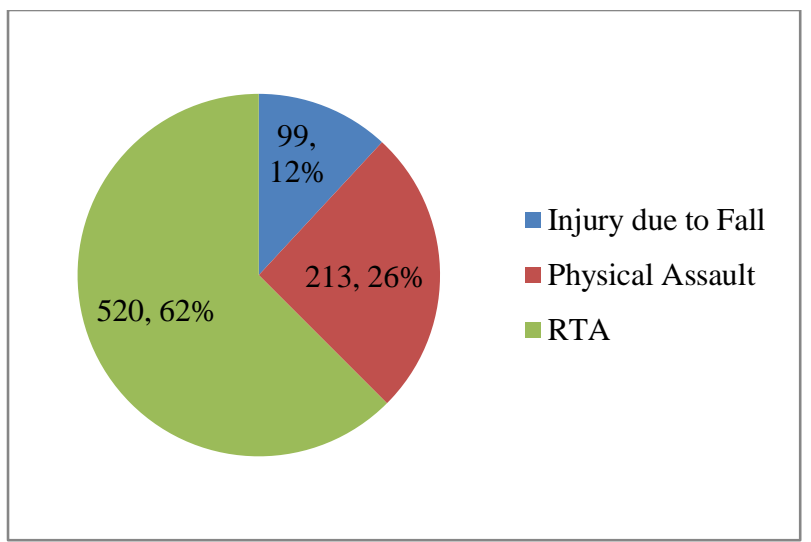

Figure 3: Demography of mode of injury

Table 1: Mean age of patients of different modes of accidents

\begin{tabular}{llll}
\hline Mode_of_injury & Mean & N & $\begin{array}{l}\text { Std. } \\
\text { Deviation }\end{array}$ \\
\hline Injury due to Fall & 34.22 & 99 & 27.466 \\
Physical Assault & 31.38 & 213 & 12.759 \\
RTA & 35.98 & 520 & 18.924 \\
\hline Total & $\mathbf{3 4 . 5 9}$ & $\mathbf{8 3 2}$ & $\mathbf{1 8 . 9 2 1}$ \\
\hline
\end{tabular}

\section{Discussion}

A huge number of patients (832) admitted through emergency department with diagnosis of some form of head injury in this part of Nepal clearly shows the amount of burden in the society. This is not just a problem of this part of the world; rather, a global epidemic especially where development is rapid. ${ }^{1,2,3,8,9,10}$ The youngsters between 20-29 years, who are supposed to be the foundation of developing countries are victimized more with this type of injuries. It is not only this study which shows majority of the youngsters being affected by head injury but also many literatures being published throughout the world shows similar finding. ${ }^{9,10}$ This study also shows gentlemen being more in number than the counter part, this might be due to them being more involved in outdoor activities in countries like Nepal. 
Table 2: Association of different variables with severity of head injury

\begin{tabular}{|c|c|c|c|c|c|}
\hline Category & Sub- category & $\begin{array}{c}\text { Mild Head } \\
\text { Injury }\end{array}$ & $\begin{array}{c}\text { Moderate Head } \\
\text { injury }\end{array}$ & Severe Head Injury & $P$ value \\
\hline \multirow{2}{*}{ Gender } & Female & 176 & 25 & 18 & \multirow{2}{*}{0.157} \\
\hline & Male & 453 & 90 & 70 & \\
\hline \multirow{3}{*}{ Mode of Injury } & Injury due to Fall & 81 & 10 & 8 & \multirow{3}{*}{0.000} \\
\hline & Physical Assault & 196 & 6 & 11 & \\
\hline & RTA & 352 & 99 & 69 & \\
\hline \multirow{10}{*}{ Age category } & $<10$ & 62 & 5 & 2 & \multirow{10}{*}{0.004} \\
\hline & $10-19$ & 76 & 12 & 18 & \\
\hline & $20-29$ & 158 & 20 & 17 & \\
\hline & $30-39$ & 123 & 22 & 16 & \\
\hline & $40-49$ & 90 & 16 & 14 & \\
\hline & $50-59$ & 59 & 15 & 7 & \\
\hline & $60-69$ & 37 & 11 & 8 & \\
\hline & $70-79$ & 13 & 5 & 4 & \\
\hline & $80-89$ & 9 & 8 & 2 & \\
\hline & $90-99$ & 2 & 1 & 0 & \\
\hline
\end{tabular}

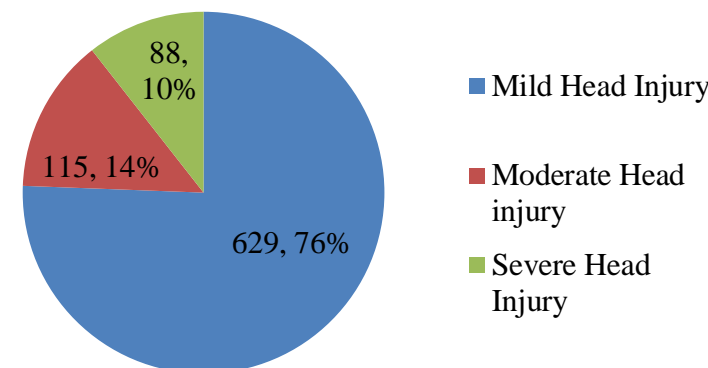

Figure 4: Distribution of severity of head injury

Majority of the head injury are due to RTA and this prevalence holds similar in most of the developing and developed countries. ${ }^{2,3,9,10}$ In this part of Nepal big highway running east to west of Nepal and northern part of Nepal with no walking lane might be the structural cause of majority of road traffic accidents.11 Also the vehicles in these highways travels in high speed; hence, increases the severity of head injury, which seems significant with Pvalue $<0.01$ in this study. The severity of head injury being more in automobile accidents than other mode of injury seems to be present globally and so is the high morbidity and mortality. ${ }^{12,13}$

Although age between 20-29 years seems to be affected more with head injury, the increasing age has increased percentage of moderate and severe head injury in this study. This also seems to be a common finding among different populations of previous literatures. ${ }^{14,15}$

\section{Conclusion}

Head injury seems to be the major cause of emergency admission in for eastern part of Nepal. Among them road traffic accidents seems to be the major burden which is more common in young gentlemen with significant number of severe head injury.

\section{References}

1. Beck LF, Dellinger AM, O'neil ME. Motor vehicle crash injury rates by mode of travel, United States: using exposure-based methods to quantify differences. American Journal of Epidemiology. 2007 Apr 21;166(2):212-8.

2. Al-Kandary N, Al-Waheeb S. Patterns of accidental deaths in Kuwait: a retrospective descriptive study from 2003-2009. BMC public health. 2015 Dec;15(1):302.

3. Sharifah Allyana SM, Zarir HZ, Abdul Rahmat AM, Siti Atiqah MF, Noor FP, Wong SV, Jamilah MJ. Recent trend of fatal motorcycle crashes in Malaysia. InProceedings of the 8th International Forum of Automotive Traffic Safety (INFATS) 2010 Dec.

4. Mishra B, Sinha ND, Sukhla SK, Sinha AK. Epidemiological study of road traffic accident cases from Western Nepal. Indian journal of community medicine: official publication of Indian Association of Preventive \& Social Medicine. 2010 Jan;35(1):115.

5. Marshall LF, Gautille T, Klauber MR, Eisenberg HM, Jane JA, Luerssen TG, Marmarou A, Foulkes MA. The outcome of severe closed head injury. egneuro, Volume 02, Issue 01, 2020 
Journal of Neurosurgery. 1991 Nov 1;75(Supplement):S28-36.

6. Jennett B, Snoek J, Bond MR, Brooks N. Disability after severe head injury: observations on the use of the Glasgow Outcome Scale. Journal of Neurology, Neurosurgery \& Psychiatry. 1981 Apr 1;44(4):28593.

7. Jennett B, Teasdale G, Braakman R, Minderhoud J, Knill-Jones R. Predicting outcome in individual patients after severe head injury. The Lancet. 1976 May 15;307(7968):1031-4.

8. Tagliaferri F, Compagnone C, Korsic M, Servadei F, Kraus JJ. A systematic review of brain injury epidemiology in Europe. Acta neurochirurgica. 2006 Mar 1;148(3):255-68.

9. Jennett B. Epidemiology of head injury. Journal of neurology, neurosurgery, and psychiatry. 1996 Apr;60(4):362.

10. Jennett B, MacMillan R. Epidemiology of head injury. $\mathrm{Br}$ Med J (Clin Res Ed). 1981 Jan 10;282(6258):101-4.

11. Schieber RA, Vegega ME. Reducing childhood pedestrian injuries. Inj Prev. 2002 Jun 1;8(suppl 1):i1-0.

12. Waters EA. Should pedal cyclists wear helmets? A comparison of head injuries sustained by pedal cyclists and motorcyclists in road traffic accidents. Injury. 1986 Nov 1;17(6):372-5.

13. Wick M, Müller EJ, Ekkernkamp A, Muhr G. The motorcyclist: easy rider or easy victim? An analysis of motorcycle accidents in Germany. The American journal of emergency medicine. 1998 May 1;16(3):320-3.

14. Luerssen TG, Klauber MR, Marshall LF. Outcome from head injury related to patient'age: A longitudinal prospective study of adult and pediatric head injury. Journal of neurosurgery. 1988 Mar 1;68(3):409-16.

15. Teasdale G, Skene A, Parker L, Jennett B. Age and outcome of severe head injury. InProceedings of the 6th European Congress of Neurosurgery 1979 (pp. 140-143). Springer, Vienna. 